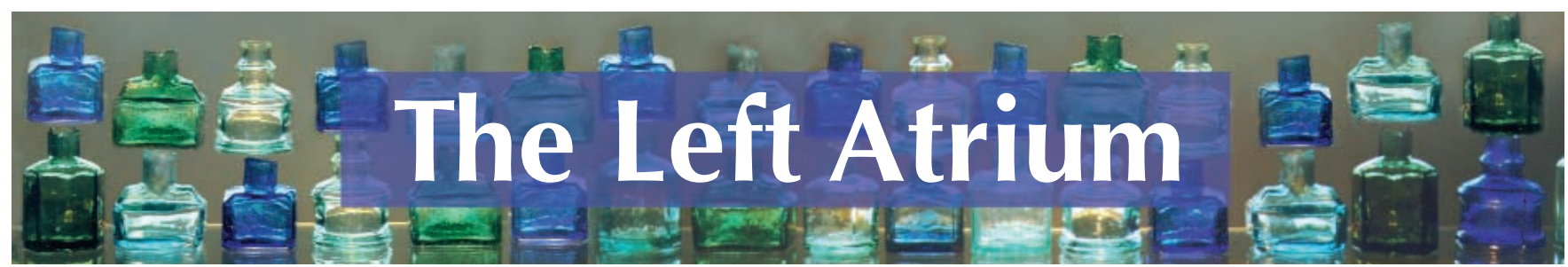

\section{Writing au volant}

A short journey by car

Liam Durcan

Montréal: Esplanade Books; 2004

200 pp \$16.95 ISBN 9-781550-651898

$\mathrm{E}$ xcluding Oliver Sacks, how many neurologists do you know who also write narratives? If I had been asked that question a short time ago, I would have come up blank. So I opened this book of short stories with some wariness: would this be the collection of a freak, its pages the product of a strange hybrid of neurologist and author, a book that found publication because of its peculiarity? But after reading the book several times, I have dispensed with these attempts at categorization. Although Liam Durcan's status as a neurologist is interesting, it is not intrinsic to the strength of his fiction. $\mathrm{He}$ deserves to be read as an author first.

The first and perhaps best of these 16 pieces is the title story. It is a peripheral account of a period in the Soviet empire. Through reputation, a dentist obtains Stalin as a patient just as Stalin is consolidating his tyrannical rule of Russia circa the first Moscow Show Trials (1936-1938). We learn of the dentist's life: its mundane domestic details (a dead father; a loving, then disinterested, wife; her drunken writer friends, a bad neighbour) and his professional struggles (being passed over for promotion at the university too many times to count). This information adds plausibility to the story. But, more importantly, we learn of Stalin and the relationship this dentist forms with his special patient. In one of the more moral passages I've read in recent fiction, the dentist in f mid-procedure frames his willingness to treat a known monster thus:

I tell myself that I will help Comrade Leader because a man in pain cannot take pity, a man in pain cannot use his wisdom to do justice, and so I set to work on draining the abscess.
It's the symbolism of the "abscess" that makes this passage particularly magnificent and believable. Eventually, the dentist starts giving Stalin suggestions to show mercy while under the influence of nitrous oxide. All of this narrative is interspersed with rather precise documentation of Stalin's dental health and a generous use of dental terminology. I suspect this is intentional: in Durcan's hands, dentistry itself becomes a metaphor, a way of understanding the world, a levelling principle. I never thought it could happen, but dentistry in Durcan's treatment even becomes heroic:

Under my gaze - will the books ever know of it? There will be stories of those who derailed trains, or fired the next first-shot and whose noisy subterfuge was heroic only in its lack of hu-

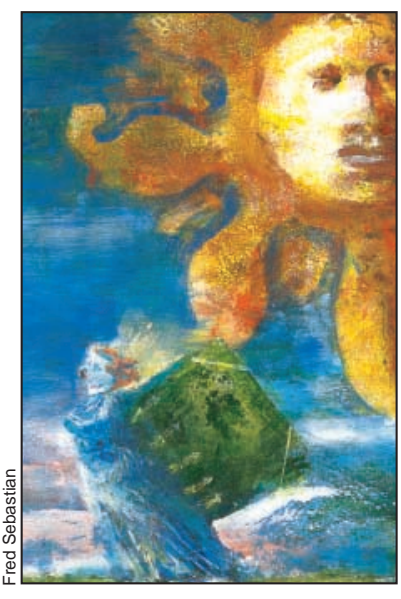
have any impact on the reader. Although it must be said that other stories are catapulting tours de force that roar forward and ricochet. In the masterful "Blood," in which a young son drives a warfarinized father to the hospital because of a bloody nose, their very movement becomes a plot device, the method they get to the hospital gaining importance as the father fatally hemorrhages. I read this story years ago in The Fiddlebead when it was first published; the kinetic, masculine, colloquial mark of Mark Jarman, fiction editor at that literary magazine, is unmistakable. Consider this inspired passage taken from the interior monologue of the young boy driving the car:

He is shouting at me, face deep in a sodden towel. His voice is muffled and faintly gurgling but there is a resonance that I could never mistake. He tells me to go through the red light - he can sense me stopping and will not have it. Go, go, he bellows from his towel. I look up over the dashboard to get a mility. What of the man who dismantles the guillotine? What of me, beseeching him as the gas flows and I undo all that his sloth and vanity have done to those smooth surfaces, what of me, scaling and probing to reduce the chance that he will pass on all the pain that he has ever had?

It would be unfair to comment that the ending of this story - what else, a murder - is capricious; that is the very point, Durcan might say. What was Stalin if not mad whim indulged?

Yet all in this volume is not up to the high standard set by "A Short Journey by Car." Some stories, such as the swimming/pregnancy meld called "Kick," are soft, plotless sketches that fail to generate enough momentum to better view of the intersection and he is at it again, for Christ's sake go, he says, the last word warbled in blood. I step on it and hear a horn blast as I pass through the intersection. For the first time I feel the power in the car, the intent in the roar beneath the floorboard and wait for the sound of a siren that doesn't come.

The sheer rhythm of this paragraph, its propulsiveness, is a performance sustained in every word of "Blood." It reads as if it were transcribed in a vision. In fact, "A Short Journey by Car" and "Blood" are enough to warrant the purchase of the book.

The gross structural problems of stories like "Kick" are not the only missteps in evidence in A Short fourney by 
Car. Most infelicities come at the level of the sentence. Durcan has a tendency to over-elaborate, as when he points the reader toward Stalin and invites him to "notice how the upper lip curls, exposing the crown of a bicuspid, its glistening tip like an inverted Matterhorn the depth of an iceberg in the Barents Sea." Either the Matterhorn or iceberg simile would have sufficed; the two together are ungainly.

This tendency extends beyond the use of compound metaphors. Durcan's prose falters because of over-elaboration when he describes a Moscow official as follows:

The senior official, head visible in my mirror, now tilts his head back ever so slightly, not suppressing his smile: a cracked incisor is visible, the work of a father's hand or the tools of one of my colleagues, either wielded in infamy.

That latter phrase (my italics) is bizarre, needless and compromises the whole description. Yet all of this can be for-

\section{My first Tensilon test}

He came in with a few pages printed out from the Internet and started talking even before he had sat down.

"I feel tired all the time, but especially in the evenings. And my face has gone droopy. I looked it up on the Internet - I think it might be myasthenia gravis. I think I need to have a test called the Tensilon test. Am I right?"

My initial thought was that this patient had Internet Print-out Syndrome. But the history did reveal symptoms typical of myasthenia. The physical examination was also convincing: he tired quickly with exercise, and even though he spoke in short bursts, his voice faded toward the end of them. So I phoned the pharmacy to get some edrophonium.

As we were waiting, I explained to the patient what the test was all about. I explained that edrophonium - Tensilon - was used to diagnose myasthenia gravis and that patients with the disease improve after administration of the drug. I also explained the cholinergic side-effects, such as abdominal cramping and diarrhea. I put in an iv, attached the patient to a cardiac monitor and put some intravenous atropine on top of the resuscitation trolley. I had read up on the test recently and was ready for all eventualities.

I called in the other junior doctors and the medical students and slowly injected the placebo: nothing happened. Then I pushed in the Tensilon: the response was dramatic. My patient's face lit up, and his eyes opened wide. Then he started to cry. The hairs stood up on the back of my neck and I could feel my eyes fill up, too. Was this my first brilliant diagnosis as a neurology trainee? I called my boss into the room.

"Prof, his facial muscles improved dramatically — it was incredible — he even started to cry."

His dry response:

"You are probably right in your diagnosis. But don't get too excited about the tears. Lacrimation is an invariable response to the cholinergic stimulation of the tear glands."

All our hearts sank, and even the patient was looking more glum. Or maybe it was just the Tensilon wearing off.

\section{Kieran Walsh}

Editorial Registrar

$B M J$ Learning

BMJ Publications

London, UK

given as the trademark intrusiveness of the first-time author who runs around, trying to batten down each hatch, safely securing everything because he doesn't trust the reader.

On a related point, it is apparent that Durcan is at his best when he is obsessional, when there are just two main characters, and when the fictional world is circumscribed, as in the case of Stalin's mouth or the catastrophic father-son car ride to the hospital. When things get more complicated, Durcan juggles his variables less competently. Characters become two-dimensional, as in the drug-study story "Control," where there's a young punk, a thirtysomething neurotic, an old bearded guy and two Asian sisters - none of whom are developed beyond that. Durcan's fictional gaze is winningly myopic; he has not yet developed the talent of panorama.

Most concerning of all is an unfortunate tendency to rely upon stock metaphor; Stalin's moustache is described as a "brush," fear under Stalin's regime as a "cold front," an car engine howls "like a hungry wolf." Eyes have an "inner fire" as they "threaten to burst from their sockets." Worse still, a woman can arrive "as spring does, quietly infusing warmth and hope, inducing tender feelings in me that I have never known."

More often, though, Durcan's powers of metaphor acquit themselves well, such as when the dentist looks into Stalin's carious mouth and through the sense of smell likens it to a "wet cement floor, a room in the basement of Nikevsky Police Station, a drain at the centre of that floor that I have heard has seen everything pass." Chilling, and thus effective.

Yes, effective. That's how I describe A Short Fourney by Car overall, a little paperback book that knows where it must go, and go quickly. Despite a few detours, it gets there. And although a canny neurologist is driving the car, you'd almost never know it.

Shane Neilson

Family Physician

Guelph, Ont. 